\title{
Coronary Drug Eluting stent: 7 Years' Experience of Norvic Hospital
}

\section{Bharat Rawat, Yadav Bhatta, J. P. Jaiswal, Shekhar Rajbhandari, Saroj Dhakal, Laxman Bhusal, Parbati Gurung, Nandita G. Acharya, Laxmi Shrestha}

Narvie International Hospital, Reathaaenvedte, Nepal

\section{Objective}

Studies have shown marked beneficial effects of coronary drug eluting stents in the prevention of re-stenosis. The present study demonstrates the experience of coronary drug eluting stents in the Norvic-International Hospital since the commencement of the PCI (Pecutaneaus Coronary Intervention) service in 2001.

\section{Method}

A retrospective analysis of all the $\mathrm{PCl}$ cases was done from the beginning i.e January 2001 till Dee 2007 to evaluate the efficiency of the coronary drug eluting stent.

\section{Results}

Altogether 387 patients had undergone $\mathrm{PCl}, 370$ (95.60\%) underwent $\mathrm{PCl}$ with coronary stenting. $337(87.08 \%)$ of the cases were elective while the remaining $33(8.52 \%)$ cases were of primary $\mathrm{PCl}$. More than two-thirds of the patients were males $302(78.01 \%)$. $270(70 \%)$ of these patients were hypertensive. 140 (36.17\%) diabetic 115 (29.71\%) dyslipidemic, 87 (22.48\%) smokers and 17 (4.39\%) had a family history positive for CAD.

Medicated stents were used in $247(66.75 \%)$ cases. The distribution according to the number of drug eluting stents used was single stents 216 (87.44\%), double stents 29 $(11.74 \%)$ and a case each of 3 and 4 stents. Drug eluting stents used were as follows: Cypher (Johnson \& Johnson) 107 (43.31\%), Infinnium (Sahajanand Medical) 64 (25.91\%), Endeavor (Medtronic) 41 (16.5\%), Xience (Guidant) 25 (10.12\%), Coroaflex (B-BRAUN 5 (2\%) and Yukon (Yukon) 5 (2\%). GP Ilb/llla was used in 100 (27\%) cases. All the patients were adequately covered with Aspirin and Clopidogrel. Four cases required post- $\mathrm{PCl}$ blood transfusion because of $\mathrm{Gl}$ bleed and/or groin haematoma There 
were altogether $4(1.03 \%)$ in-hospital mortalities; 1 Elective, $\mathrm{PCl}$ and 2 Primary and one rescue $\mathrm{PCl}$ cases. Out of 4 deaths 2 were patients who were diagnosed as $\mathrm{AMI}$ in Carcinogenic shock. There was no case of Acute or Sub acute stent thrombosis 1 patient died because of possible intracranial bleed.

All the patients were followed up for 3 to 6 months and were symptom free Check angiogram done on 98 patients at 6 months to 1 year follow-up revealed patent Stents in all but one patient (98.54).

\section{Conclusions}

Our findings show that the drug eluting stents are safe and did not show any added risk of acute or sub acute stent thrombosis. There is significant reduction in rastenosis rate with the use of DES. 